\title{
Relationship of Parental and Adolescents' Screen Time to Self-Rated Health: A Structural Equation Modeling
}

Health Education \& Behavior 2018, Vol. 45(5) 764-77। (C) 2018 Society for Public Health Education Article reuse guidelines: sagepub.com/journals-permissions DOI: | 0.1 | $77 / 1090198 \mid 18757825$ journals.sagepub.com/home/heb (S)AGE

\author{
André O. Werneck, BSc' (D), Danilo R. Silva, PhD², \\ Ricardo R. Agostinete, $\mathrm{MSc}^{3}$, Rômulo A. Fernandes, $\mathrm{PhD}^{3}$, \\ Enio R. V. Ronque, PhD', Adewale L. Oyeyemi, PhD ${ }^{4}$, \\ and Edilson S. Cyrino, PhD'
}

\begin{abstract}
Aim. To investigate the association of parental and adolescents' screen time with self-rated health and to examine the mediating effects of psychosocial factors (social relationships and distress) on this association. Method. A cross-sectional study was conducted among 984 Brazilian adolescents (10- to 17-year-olds). Self-rated health, screen time (adolescents and parental), and perception of social relationships and distress were evaluated through self-report questionnaires. Structural equation modeling was adopted to investigate the pathways of the relationship between adolescents' screen time and selfrated health. Results. Adolescents' screen time was directly and negatively related to self-rated health only in boys $(r=-0.158$, $p=.015)$. In girls, screen time was related to self-rated health through distress $(r=-0.188, p=.007)$ and social relationships $(r=0.176, p=.008)$. The models fit was adequate $\left(\chi^{2} / d f \leq 3.0\right.$, root mean square error of approximation $<0.08$, comparative fit index $>0.90$, and Tucker-Lewis Index $>0.90$ ). Conclusions. Higher screen time was associated with poor self-rated health in boys, while in girls, psychosocial factors mediated the adverse relationships between screen time and self-rated health.
\end{abstract}

\section{Keywords}

motor activity, physical activity, sedentary lifestyle

Self-rated health (SRH) is an important indicator of general health status, which is related to both psychological and physical outcomes (Idler \& Benyamini, 1997) and has been associated with mortality (higher risk of mortality associated with poorer SRH; DeSalvo, Bloser, Reynolds, He, \& Muntner, 2006; Idler \& Benyamini, 1997). Although the evidence is less clear in children and adolescents, there is a possibility that the precursors of poor SRH often develop in the early years of life (Hamer, Yates, Sherar, Clemes, \& Shankar, 2016). Therefore, it is important to understand the correlates of SRH in adolescence because this is a critical period for greater physical, behavioral, and psychosocial changes (Mechanic \& Hansell, 1987) that can influence current and future health (Bopp, Braun, Gutzwiller, Faeh, \& Group, 2012).

Among the several correlates (biological, mental outcomes and behavioral factors) of SRH, an emergent and important modifiable risk factor relevant to prevention of chronic diseases is sedentary behavior. Studies have showed that sitting time is related to mortality independent of physical activity levels (Katzmarzyk, Church, Craig, \& Bouchard, 2009), even though there could be a compensation relationship between physical activity and sitting time (Ekelund et al., 2016). The most common sedentary behavior among youth is the screen time, such as video game, computer time, and television viewing (Sun et al., 2015). A recent 6-year cohort study identified an increased risk of mortality in adults with higher TV viewing time, regardless of physical activity and other variables (Turi et al., 2018). During childhood and adolescence, screen time is also related to several metabolic risk factors (e.g., high blood pressure, poorer lipid profile, high visceral fat; Byun, Dowda, \& Pate, 2012; Martínez-Gómez et al., 2010). Also, large amount of screen time in adolescence is

\footnotetext{
'State University of Londrina-UEL, Londrina, Brazil

${ }^{2}$ Federal University of Sergipe-UFS, São Cristóvão, Brazil

${ }^{3}$ São Paulo State University-UNESP, Presidente Prudente, Brazil

${ }^{4}$ University of Maiduguri, Maiduguri, Borno State, Nigeria

Corresponding Author:

André O. Werneck, Physical Education Department, Londrina State University, Rodovia Celso Garcia Cid, km 380, Campus Universitário, Londrina, Paraná 8605I-990, Brazil.

Email: andreowerneck@gmail.com
} 
negatively associated with mental health indicators such as depressive symptoms, stress, and worse social relationships perception (Gunnell et al., 2016; Liu, Wu, \& Ming, 2015; Maras et al., 2015). However, evidence was mainly from studies conducted in the high-income countries (Byun et al., 2012; Carson et al., 2016; Martínez-Gómez et al., 2010; Tremblay et al., 2011). Thus, it is also an important research priority to understand the impact of screen time on the health status of adolescents in developing countries.

Although there is evidence that higher duration of TV viewing and/or screen time are associated with unfavorable health outcomes among adolescents (Carson et al., 2016; Tremblay et al., 2011), the potential pathways for the relationships between screen time and SRH have been relatively unstudied. While Herman, Hopman, and Sabiston (2015) found an inverse direct relationship between screen time of adolescents and SRH, this relationship could occur through other pathways including poor psychological state arising from short sleep duration (Barlett, Gentile, Barlett, Eisenmann, \& Walsh, 2012) and body image dissatisfaction from social networks and TV programs (Añez et al., 2016). Moreover, poor parental modeling and weak parental regulation on screen time, among others, could predict more screen time in adolescence (Gebremariam et al., 2012; Mielke, Brown, Nunes, Silva, \& Hallal, 2016; Totland et al., 2013). Yet it remains unclear how parental screen time influences or mediates the relationship between adolescents' screen time and SRH (Richards, McGee, Williams, Welch, \& Hancox, 2010). A better understanding of the pathways through which screen time affects health outcomes in adolescence could contribute to the development of effective and comprehensive interventions to reduce sedentary behavior and improve adolescents' health. Therefore, the aims of this study were to investigate the direct association of parental and adolescents' screen time with adolescent SRH and to examine if this association is mediated by psychosocial factors (i.e., perceived social relationships and distress constructs) using a structural equation modeling approach.

\section{Methods}

\section{Sample}

The present scientific article is based on a cross-sectional epidemiological school-based study involving Brazilian adolescents aged between 10 and 17 years, enrolled in public schools of Londrina/PR. Londrina has 506,701 inhabitants, a medium human development index of 0.778 , and a gross domestic product per capita of US $\$ 8530.77$ (both indices are above the average value for most Brazilian's cities; Instituto Brasileiro de Geografia e Estatística, 2013). The procedures involved in this study were approved by the Ethical Board Committee of the Londrina State University (Process number 10655/2012).

For sampling process, all public schools of the city were stratified into geographical locations (north, south, east, west, and center), and 2 schools were randomly selected from each location (10 schools were selected and all agreed to participate). Subsequently, between four and five classes in the selected schools were randomly selected and all students within the classes (except those using prescription medicine or undergoing treatment for an illness) were invited to participate in the study. Students who failed to return a consent form signed by at least a parent were ineligible and thus excluded from the survey. Questionnaires were filled out anonymously by the adolescents themselves in their classrooms according to the instructions provided by the research staff assigned to each of the schools. After fieldwork, 1,395 adolescents were eligible to participate, but 411 failed to provide all required data for the analysis of this study and were excluded. Thus, the final sample comprised 984 adolescents, with a response rate of $70.5 \%$. For parents' assessment, all eligible adolescents delivered similar questionnaires (that gauged parental screen time) to their parents or guardians at home. The adolescents were oriented and tasked with returning their parents questionnaire back to the research staff in their schools. The adolescents and their parents completed the questionnaires in the same week. Further details about the project are available elsewhere (Silva et al., 2016).

\section{Measures}

The outcome (SRH) and exposure (parental and adolescents' screen time, perceived social relationships, and distress constructs) variables were measured by self-report questionnaires. The 7-day test-retest reliability of the measures was tested through repeated application of the questionnaires in a subsample $(n=74)$ of the participants with similar characteristics to the larger sample (descriptive results of the psychometric sample are not shown in the table). The computed intraclass correlation coefficient (ICC) for the questionnaires ranged between 0.50 and 0.80 , which were acceptable values, given the nature of the questionnaires that the score can change according the day of measurement, due to several reasons as perception of social relationships and distress.

\section{Self-Rated Health}

SRH was assessed through the following question "In general, how do you consider your health?" Responses were on a 4-point Likert-type scale ranging from $1=$ bad to $4=$ excellent. The single-item question had good test-retest reliability $(\mathrm{ICC}=0.73)$ in our sample.

\section{Parental and Adolescent Screen Time}

Parental and adolescents screen time were assessed through four questions asking about how many hours a day were spent watching television and how many hours a day were spent using computer and video games on weekdays and weekends. The final indicator was the mean of these 
questions separately for the parents and adolescents. Items on the questionnaire showed very good evidence of testretest reliability in the sample $(\mathrm{ICC}=0.79)$.

\section{Perception of Social Relationships}

Self-perception about the relationship with friends, families, and professors were assessed through the following three questions: "Regarding your relationship with your classmates and friends, you are ...," "Regarding your relationship with your family, you are ...,", and "Regarding your relationship with your professors, you are ...." Responses were on a 4-point Likert-type scale ranging from $1=$ very unsatisfied to $4=$ very satisfied. The three questions demonstrated acceptable test-retest reliability with ICC of $0.50,0.53$, and 0.69 , respectively in our sample.

\section{Distress Constructs}

Sadness was measured through the following question: "How often do you feel sad or depressed?" Responses were on a 4-point Likert-type scale ranging from $1=$ very frequently to $4=$ rarely. The reliability of the question was acceptable (ICC $=0.62$ ) in our sample. Similarly, information regarding stress was collected through the following question "How often do you feel stressed?"Responses were on a 4-point Likert-type scale ranging from $1=$ very frequently to $4=$ rarely. The test-retest reliability of the question was very good $(\mathrm{ICC}=0.80)$ in our sample.

\section{Statistical Procedures}

Descriptive statistics (mean and standard deviation) were used to describe characteristics of the sample. The MannWhitney test was used to compare groups (boys and girls) in terms of SRH, parental and adolescents' screen time, perceptions of social relationships, and distress constructs (sadness and stress). Thereafter, to analyze the correlation between variables, we conducted a Pearson correlation using STATA 14.0 software.

Structural equation modeling (SEM) was used to investigate the pathways of the relationship between parental screen time, screen time of adolescents, social relationships, distress constructs, and SRH. Since the endogenous variables in the models were normally distributed, with skewness varying between 0.001 and 0.1 and kurtosis varying between 0.001 and 0.7 , but with considerable missing data for the parental ( maternal $=411$, paternal $=514)$ variables, the full-information maximum-likelihood method (to deal with the missing data) was used to determine the estimates of the parameters. The SEM was conducted using AMOS 22.0 software. Given that the variables in the model were not significantly different (Mann-Whitney test $p$ values $>.05$ ) between missing data and nonmissing data, there was no identifiable pattern of missingness from the data in the model. The results of the
SEM are presented with standardized regression coefficients $(r)$. To estimate the overall fit model, we used the following parameters: chi-square test $\left(\chi^{2}\right), \chi^{2} /$ degrees of freedom $\left(\chi^{2} / d f\right)$, root mean square error of approximation (RMSEA), comparative fit index (CFI) and Tucker-Lewis index (TLI). Values $<3.0$ for $\chi^{2} / d f,<0.08$ for RMSEA, $>0.90$ for CFI, and $>0.90$ for TLI indicate acceptable (adequate) model fit. Moreover, values $<2.0$ for $\chi^{2} / d f,<0.06$ for RMSEA, $>0.95$ for CFI, and $>0.95$ for TLI were considered good values of fit (Kline, 2005; Lei \& Wu, 2007; Marsh \& Hocevar, 1985).

The theoretical model underpinning the study is described in Figure 1. Parental screen time, adolescents screen time, and psychosocial factors (social relationships and distress construct) were the predictors, and SRH was the theoretical outcome in the model. Because the predictor variables are known to be different between boys and girls (Costigan, Barnett, Plotnikoff, \& Lubans, 2013; Totland et al., 2013), the model was stratified by sex to facilitate qualitative comparisons between boys and girls. A significance level of $95 \%$ was adopted to determine significant associations.

\section{Results}

Final sample was composed of 984 adolescents (405 boys and 579 girls) between 10 and 17 years old (mean age $=12.9$ years; $95 \%$ CI $[12.8,13.0])$. With regard to parents, 984 mothers (chronological age range, 24-66 years; mean age, $38.4 \pm 7.0$ years) and 803 fathers (chronological age range, 23-76 years; mean age, $41.3 \pm 8.1$ years) participated in the study. Boys reported higher SRH $(p<.001)$, social relationship with family $(p<.001)$, and time in computer and video game use $(p<.001)$ than girls. Compared with boys, girls reported higher stress $(p<.001)$ and sadness $(p<.001)$. Detailed characteristics of the sample are presented in Table 1. The correlations between variables included in the model are shown in Table 2. For boys, adolescent daily video game/ computer time was negatively related with SRH $(r=-0.14$; $p<.05)$, as was paternal screen time $(r=-0.12 ; p<.05)$. Moreover, sadness and personal relationships with friends and family were related to SRH in both sexes $(p<.05)$. Only in girls was SRH negatively related to stress $(r=-0.09$; $p<.05$ ).

The relationships under SEM approach are presented in Figures 2 and 3 for boys and girls, respectively. In general, both sex-specific models demonstrated adequate fit based on the criteria of $\chi^{2} / d f$ (1.56 for boys and 2.0 for girls), RMSEA ( 0.03 for boys and 0.04 for girls), CFI ( 0.95 for boys and 0.94 for girls), and TLI ( 0.90 for boys and 0.89 for girls). Adolescents' screen time was directly and negatively related to SRH only in boys $(r=-0.158, p=.015)$. Although adolescents' screen time was significantly related to distress ( $r=$ $0.216, p=.043$ ) in boys, its pathways to SRH were not significantly explained by distress. In girls, adolescents' screen time was positively associated with distress $(r=0.357, p=$ $.028)$, which in turn significantly predicted poor SRH $(r=$ 


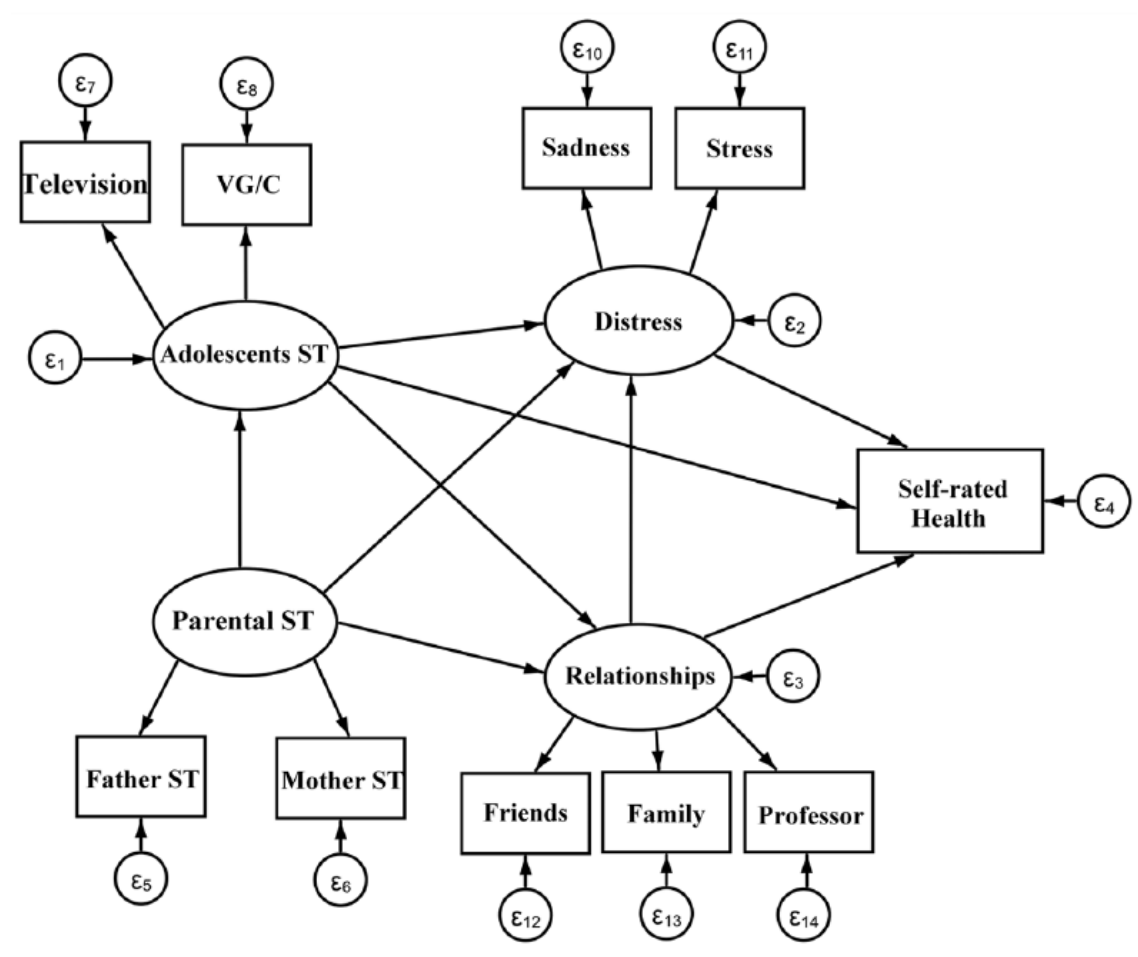

Figure I. Theoretical model for the association between parental screen time, adolescents' screen time, distress, relationship perceptions, and adolescents' self-rated health. VG = video game; $\mathrm{ST}=$ screen time; $\mathrm{C}=$ computer.

Table I. Descriptive Measures of Variables Included in the Models.

\begin{tabular}{lcc}
\hline Variable & Boys $(n=405), M(S D)$ & Girls $(n=579), M(S D)$ \\
\hline Chronological age (years) & $13.0(1.6)$ & $12.9(I .5)$ \\
Self-rated health (I-4 scale) & $2.1(0.8)^{*}$ & $1.9(0.7)$ \\
Relationship perception with friends (I-4 scale) & $2.3(0.7)$ & $2.3(0.7)$ \\
Relationship perception with family (I-4 scale) & $2.5(0.8)^{*}$ & $2.3(0.8)$ \\
Relationship perception with professor (I-4 scale) & $1.7(0.9)$ & $1.7(0.9)$ \\
Stress (I-4 scale) & $1.2(0.9)^{*}$ & $1.6(0.9)$ \\
Sadness (I-4 scale) & $1.2(0.7)^{*}$ & $1.5(0.8)$ \\
Adolescents TV watching (hours/day) & $4.7(3.5)$ & $4.6(3.1)$ \\
Adolescents computer and video game using (hours/day) & $4.1(3.8)^{*}$ & $3.1(3.1)$ \\
Paternal screen time (hours/day) & $3.8(3.6)$ & $3.7(3.2)$ \\
Maternal screen time (hours/day) & $3.7(3.6)$ & $3.6(2.7)$ \\
\hline
\end{tabular}

Note. Mann-Whitney test was used to compare groups. SD = standard deviation. $*_{p}<.05$.

$-0.188, p=.007)$. Moreover, social relationships also predicted better SRH in girls $(r=0.176, p=.008)$, and part of the association passed through distress. Also, parental screen time was significantly related to adolescents' screen time $(r=0.381, p=.002)$ in girls but not in boys.

\section{Discussion}

The purpose of this cross-sectional study was to investigate the pathways of the relationship of screen time and psychosocial indicators (social relationships and distress) with SRH in adolescents. We found that higher screen time was negatively associated with SRH in boys. On the other hand, among girls, psychosocial indicators mediated the relationship between screen time and SRH. Although there are few studies to directly compare the current study, our findings suggest that the relationship between screen time and health among adolescents may be complex and could be dependent on gender and indirectly influenced by psychosocial factors including social relationships and distress. 
Table 2. Correlations Between Variables Included in the Models.

\begin{tabular}{|c|c|c|c|c|c|c|c|c|c|c|}
\hline Variable & 1 & 2 & 3 & 4 & 5 & 6 & 7 & 8 & 9 & 10 \\
\hline \multicolumn{11}{|l|}{ Boys $(n=405)$} \\
\hline I. Self-rated health & - & & & & & & & & & \\
\hline $\begin{array}{l}\text { 2. Relationship perception with } \\
\text { friends }\end{array}$ & $0.10 *$ & - & & & & & & & & \\
\hline $\begin{array}{l}\text { 3. Relationship perception with } \\
\text { family }\end{array}$ & $0.14^{*}$ & $0.26 *$ & - & & & & & & & \\
\hline $\begin{array}{l}\text { 4. Relationship perception with } \\
\text { professor }\end{array}$ & 0.03 & $0.13^{*}$ & $0.20 *$ & - & & & & & & \\
\hline 5. Stress & -0.06 & -0.04 & $-0.22^{*}$ & $-0.23^{*}$ & - & & & & & \\
\hline 6. Sadness & $-0.15^{*}$ & -0.05 & $-0.20 *$ & $-0.10 *$ & $0.34^{*}$ & - & & & & \\
\hline 7. Adolescents TV watching & -0.06 & -0.03 & -0.01 & $-0.08 *$ & $0.12 *$ & 0.06 & - & & & \\
\hline $\begin{array}{l}\text { 8. Adolescents computer and } \\
\text { video game using }\end{array}$ & $-0.14^{*}$ & $-0.08 *$ & -0.06 & $-0.08^{*}$ & $0.12 *$ & 0.07 & $0.31 *$ & - & & \\
\hline 9. Paternal screen time & $-0.12^{*}$ & 0.01 & -0.01 & -0.06 & 0.04 & -0.02 & 0.101 & $0.13^{*}$ & - & \\
\hline 10. Maternal screen time & -0.011 & 0.01 & 0.04 & -0.06 & 0.02 & 0.02 & $0.11 *$ & 0.06 & $0.23^{*}$ & - \\
\hline \multicolumn{11}{|l|}{ Girls $(n=579)$} \\
\hline I. Self-rated health & - & & & & & & & & & \\
\hline $\begin{array}{l}\text { 2. Relationship perception with } \\
\text { friends }\end{array}$ & $0.16^{*}$ & - & & & & & & & & \\
\hline $\begin{array}{l}\text { 3. Relationship perception with } \\
\text { family }\end{array}$ & $0.16 *$ & $0.33^{*}$ & - & & & & & & & \\
\hline $\begin{array}{l}\text { 4. Relationship perception with } \\
\text { professor }\end{array}$ & $-0.12 *$ & 0.07 & $0.20 *$ & - & & & & & & \\
\hline 5. Stress & $-0.09 *$ & $-0.08^{*}$ & $-0.17 *$ & $-0.18^{*}$ & - & & & & & \\
\hline 6. Sadness & $-0.21^{*}$ & $-0.11 *$ & $-0.26 *$ & $-0.15^{*}$ & $0.38^{*}$ & - & & & & \\
\hline 7. Adolescents TV watching & -0.03 & -0.04 & 0.04 & -0.03 & $0.10^{*}$ & 0.06 & - & & & \\
\hline $\begin{array}{l}\text { 8. Adolescents computer and } \\
\text { videogame using }\end{array}$ & -0.02 & $0.11 *$ & -0.02 & $-0.09 *$ & 0.03 & $0.12^{*}$ & $0.13^{*}$ & - & & \\
\hline 9. Paternal screen time & 0.04 & -0.01 & -0.03 & -0.01 & 0.01 & -0.01 & 0.05 & $0.09 *$ & - & \\
\hline 10. Maternal screen time & -0.04 & -0.03 & -0.07 & -0.05 & 0.06 & 0.07 & $0.12 *$ & $0.14 *$ & $0.45^{*}$ & - \\
\hline
\end{tabular}

Note. Screen time information is presented in hours per day. $* p<.05$.

Sedentary behavior is a complex behavior, characterized by a sitting and reclining posture (Sedentary Behaviour Research Network, 2012). The prevalence of sedentary time in children and adolescents, especially in the screen time domain, is increasing worldwide (Bucksch et al., 2016). Several factors including the number of televisions in the house, social relationships, nutritional status, parental influence, among others are thought to be the drivers of higher screen time among youths (Gebremariam et al., 2012; Mielke et al., 2016). Sedentary behavior is also a recognized driver of cardiovascular risk (Katzmarzyk et al., 2009). Screen time, especially television viewing, is associated with cardiovascular risk factors in adolescents, independent of physical activity levels (Byun et al., 2012; Martínez-Gómez et al., 2010).

Beyond biological outcomes that can be negatively influenced by screen time during adolescence, psychological factors such as well-being, stress, and depression symptoms can also influence adolescents' screen time (Gunnell et al., 2016; Maras et al., 2015). We found that greater screen time was associated with greater psychological distress (sadness and stress feelings) and worse social relationships. Similarly, indicators of distress and social relationships were significant mediators of the relationship between screen time and SRH among girls. Also, we observed that worse social relationship was directly related to a lower SRH in both sexes, and, in girls, distress was related with SRH. These findings reinforce what represents SRH, which is recognized as an outcome of physical and psychological health (Idler \& Benyamini, 1997). Therefore, given that higher screen time in our study was related to more psychological distress, which in turn was negatively related to SRH, consequently, screen time could be considered an important negative correlate of SRH in adolescence.

Our finding that the relationships between adolescents' screen time and SRH was explained through the pathways of psychosocial constructs, especially in girls, has public health implications. Considering the pervasive health consequences of high screen time in adolescents, this evidence can help inform the development of effective interventions to reduce 


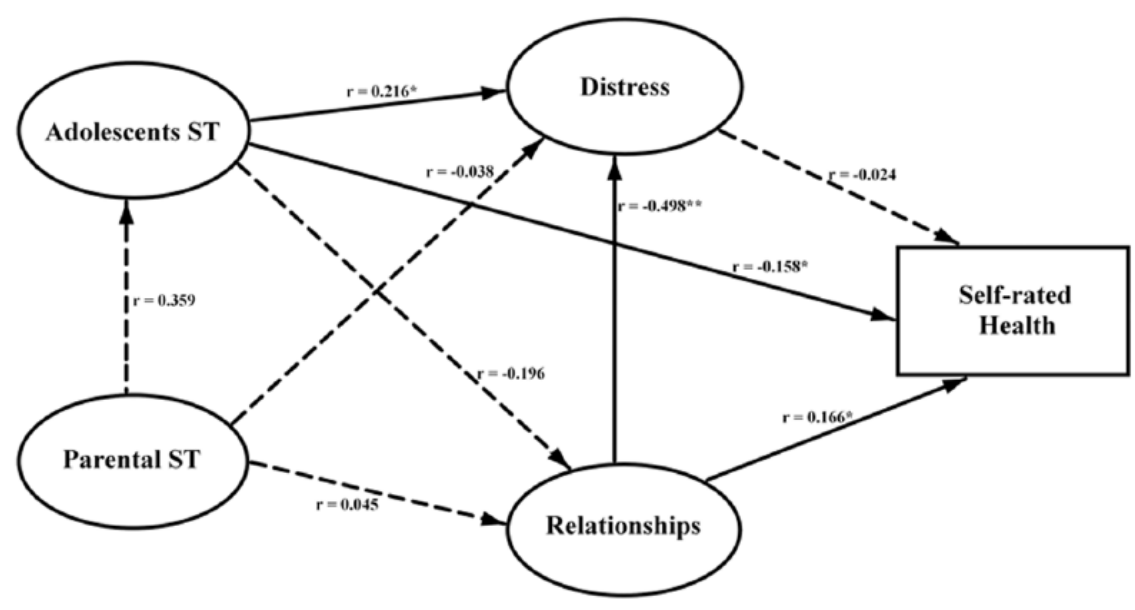

Figure 2. Final model for the association between screen time, distress, relationships perception, and self-rated health in boys. ST = screen time. Data are presented with standardized coefficients $(r)$. Fit parameters: $\chi^{2}=42.22(p=.03 \mathrm{I}) ; \chi^{2} / d f=1.56$; root mean square error of approximation $($ RMSEA $)=0.03$; comparative fit index $(C F I)=0.95$; Tucker-Lewis index $(\mathrm{TLI})=0.90$.

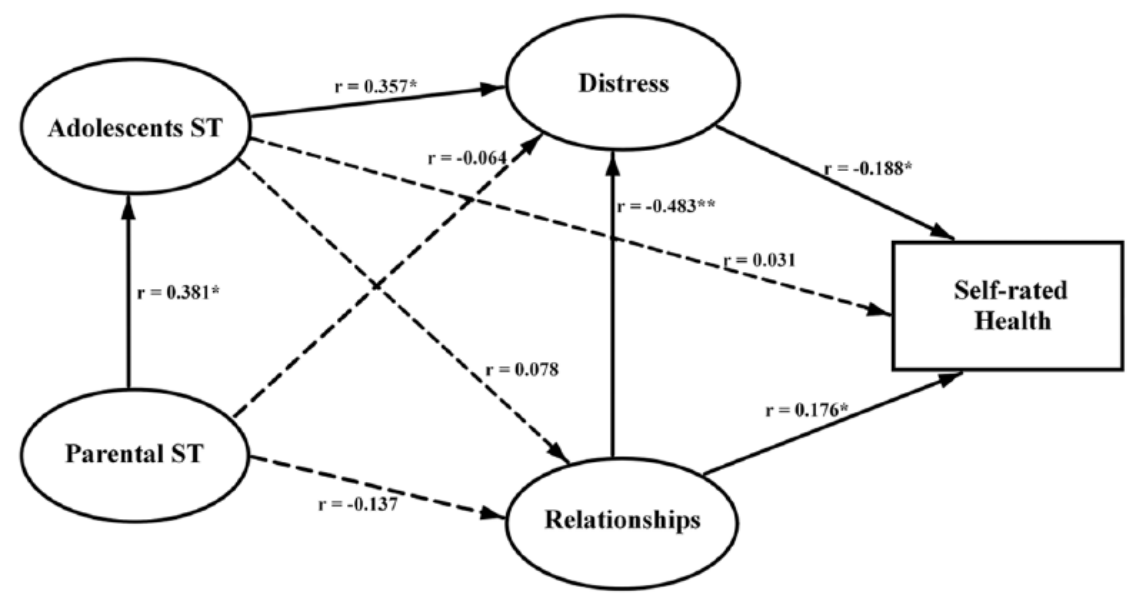

Figure 3. Final model for the association between screen time, distress, relationships perception, and self-rated health in girls. ST $=$ screen time. Data are presented with standardized coefficients $(r)$. Fit parameters are $\chi^{2}=53.92(p=.002) ; \chi^{2} / d f=2.00 ;$ root mean square error of approximation $(\mathrm{RMSEA})=0.04$; comparative fit index $(\mathrm{CFI})=0.94$; Tucker-Lewis index $(\mathrm{TLI})=0.89$.

screen-based sedentary behavior and consequently contribute to better and improved health status in Brazilian adolescents. For practical application, behavioral interventions to reduce screen time should focus on strategies to increase recreational and leisure time physical activity among Brazilian adolescents. Such interventions can minimize psychological disorders and consequently improve SRH (Spruit, Assink, van Vugt, van der Put, \& Stams, 2016). Also, recreational interventions can positively enhance the motivation of adolescents to reduce screen time (Babic et al. 2016).

Despite the importance of our findings to understanding the complex relationship between screen time and adolescents' health status, it is important to acknowledge the limitations of the present study. Regarding our methods, we adopted subjective indicators of sedentary behavior, psychosocial factors, and SRH, which are prone to measurement error and respondent's bias. However, it is important to emphasize that test-retest reliability of items in the study questionnaires was generally good and acceptable $(\mathrm{ICC}=$ $0.50-0.80)$. Another potential limitation of the study is the large number of missing data from the parental questionnaire. However, there were no identifiable patterns to the missing data, and the adopted analytic strategy of full-information maximum likelihood was robust to ensure sufficient power for the sex-specific results. Another limitation was the cross-sectional design nature of the study, which does not allow for interpretation of causality between examined variables. Indeed, potential reverse causality could account for some of the findings in the present study. For example, it is possible that worse psychological distress and poor social relationship may promote more time in screen viewing, which in turn may lead to poor SRH. 
In conclusion, higher screen time was negatively associated with SRH in boys, while in girls, poor psychosocial factors seem to negatively mediate the adverse relationships between screen time and SRH. Considering the avalanche of screen-based technological devices in modern society, it is important to develop interventions that can be used by parents, professors, and health/education professionals to reduce screen time and combat sedentary behavior during childhood and adolescence. Such interventions could involve strategies focusing on enhancing psychosocial support to break screen time and increase health-related physical activity and active play at leisure and physical/health education in schools.

\section{Authors' Note}

All procedures performed in the studies involving human participants were in accordance with the ethical standards of the institutional and/or national research committee and with the 1964 Helsinki declaration and its later amendments or comparable ethical standards. Informed consent was obtained from all individual participants and participants' parents included in the study.

\section{Acknowledgments}

The authors thank Alessandra Okino, Jair Oliveira, Danielle Venturini, and Décio Barbosa for research support; Crisieli Tomeleri, Mariana Carnelossi, and Sandra Kawaguti for acquisition of data; Coordination for the Improvement of Higher Education Personnel (CAPES/Brazil) for scholarships (D.R.S.); and National Council of Scientific and Technological Development (CNPq/Brazil) for funding the project (483867/2009-8) and for scholarship of scientific initiation (A.O.W.) and productive research (E.R.V.R., E.S.C., and R.A.F.).

\section{Declaration of Conflicting Interests}

The authors declared no potential conflicts of interest with respect to the research, authorship, and/or publication of this article.

\section{Funding}

The authors disclosed receipt of the following financial support for the research, authorship, and/or publication of this article: This study was funded by Brazilian Council of Scientific and Technological Development (grant number: 483867/2009-8).

\section{ORCID iD}

André O. Werneck iD https://orcid.org/0000-0002-9166-4376

\section{References}

Añez, E., Fornieles-Deu, A., Fauquet-Ars, J., López-Guimerà, G., Puntí-Vidal, J., \& Sánchez Carracedo, D. (2016). Body image dissatisfaction, physical activity and screen-time in Spanish adolescents. Journal of Health Psychology, 23, 36-47. doi: $10.1177 / 1359105316664134$

Babic, M. J., Smith, J. J., Morgan, P. J., Lonsdale, C., Plotnikoff, R. C., Eather, N., . . L Lubans, D. R. (2016). Intervention to reduce recreational screen-time in adolescents: Outcomes and mediators from the "Switch-Off 4 Healthy Minds" (S4HM) cluster randomized controlled trial. Preventive Medicine, 91, 50-57. doi:10.1016/j.ypmed.2016.07.014

Barlett, N. D., Gentile, D. A., Barlett, C. P., Eisenmann, J. C., \& Walsh, D. A. (2012). Sleep as a mediator of screen time effects on US children's health outcomes. Journal of Children and Media, 6, 37-50. doi:10.1080/17482798.2011.633404

Bopp, M., Braun, J., Gutzwiller, F., Faeh, D., \& Group, S. N. C. S. (2012). Health risk or resource? Gradual and independent association between self-rated health and mortality persists over 30 years. PLoS One, 7, e30795. doi:10.1371/journal. pone.0030795

Bucksch, J., Sigmundova, D., Hamrik, Z., Troped, P. J., Melkevik, O., Ahluwalia, N., . . Inchley, J. (2016). International trends in adolescent screen-time behaviors from 2002 to 2010. Journal of Adolescence Health, 58, 417-425. doi:10.1016/j.jadohealth.2015.11.014

Byun, W., Dowda, M., \& Pate, R. R. (2012). Associations between screen-based sedentary behavior and cardiovascular disease risk factors in Korean youth. Journal of Korean Medical Science, 27, 388-394. doi:10.3346/jkms.2012.27.4.388

Carson, V., Hunter, S., Kuzik, N., Gray, C. E., Poitras, V. J., Chaput, J. P., . . Tremblay, M. S. (2016). Systematic review of sedentary behaviour and health indicators in school-aged children and youth: An update. Applied Physiology Nutrition and Metabolism, 41(6 Suppl. 3), S240-S265. doi:10.1139/ apnm-2015-0630

Costigan, S. A., Barnett, L., Plotnikoff, R. C., \& Lubans, D. R. (2013). The health indicators associated with screen-based sedentary behavior among adolescent girls: A systematic review. Journal of Adolescent Health, 52, 382-392. doi:10.1016/j.jadohealth.2012.07.018

DeSalvo, K. B., Bloser, N., Reynolds, K., He J., \& Muntner, P. (2006). Mortality prediction with a single general self-rated health question. Journal of General Internal Medicine, 21, 267-275.

Ekelund, U., Steene-Johannessen, J., Brown, W. J., Fagerland, M. W., Owen, N., Powell, K. E., . . Group, L. S. B. W. (2016). Does physical activity attenuate, or even eliminate, the detrimental association of sitting time with mortality? A harmonised meta-analysis of data from more than 1 million men and women. Lancet, 388, 1302-1310. doi:10.1016/S01406736(16)30370-1

Gebremariam, M. K., Totland, T. H., Andersen, L. F., Bergh, I. H., Bjelland, M., Grydeland, M., .. . Lien, N. (2012). Stability and change in screen-based sedentary behaviours and associated factors among Norwegian children in the transition between childhood and adolescence. BMC Public Health, 12, 104. doi:10.1186/1471-2458-12-104

Gunnell, K. E., Flament, M. F., Buchholz, A., Henderson, K. A., Obeid, N., Schubert, N., \& Goldfield, G. S. (2016). Examining the bidirectional relationship between physical activity, screen time, and symptoms of anxiety and depression over time during adolescence. Preventive Medicine, 88, 147-152. doi:10.1016/j. ypmed.2016.04.002

Hamer, M., Yates, T., Sherar, L. B., Clemes, S. A., \& Shankar, A. (2016). Association of after school sedentary behaviour in adolescence with mental wellbeing in adulthood. Preventive Medicine, 87, 6-10. doi:10.1016/j.ypmed.2016.02.021

Herman, K. M., Hopman, W. M., \& Sabiston, C. M. (2015). Physical activity, screen time and self-rated health and mental 
health in Canadian adolescents. Preventive Medicine, 73, 112116. doi:10.1016/j.ypmed.2015.01.030

Idler, E. L., \& Benyamini, Y. (1997). Self-rated health and mortality: A review of twenty-seven community studies. Journal of Health and Social Behavior, 38(1), 21-37.

Instituto Brasileiro de Geografia e Estatística. (2013). Gross domestic product of municipalities. Retrieved from http://www.ibge. gov.br/cidadesat/xtras/perfil.php? codmun $=411370 \&$ search $=$ parana

Katzmarzyk, P. T., Church, T. S., Craig, C. L., \& Bouchard, C. (2009). Sitting time and mortality from all causes, cardiovascular disease, and cancer. Medicine \& Science in Sports \& Exercise, 41, 998-1005. doi:10.1249/MSS.0b013e3181930355

Kline, R. (2005). Principles and practice of structural equation modeling (2nd ed.). New York, NY: Guild Ford Press.

Lei, P.-W., \& Wu, Q. (2007). Introduction to structural equation modeling: Issues and practical considerations. Educational Measurement: Issues and Practice, 26(3), 33-43.

Liu, M., Wu, L., \& Ming, Q. (2015). How does physical activity intervention improve self-esteem and self-concept in children and adolescents? Evidence from a meta-analysis. PLoS One, 10, e0134804. doi:10.1371/journal.pone.0134804

Maras, D., Flament, M. F., Murray, M., Buchholz, A., Henderson, K. A., Obeid, N., \& Goldfield, G. S. (2015). Screen time is associated with depression and anxiety in Canadian youth. Preventive Medicine, 73, 133-138. doi:10.1016/j.ypmed.2015.01.029

Marsh, H. W., \& Hocevar, D. (1985). Application of confirmatory factor analysis to the study of self-concept: First- and higher order factor models and their invariance across groups. Psychological Bulletin, 97, 562-582. doi:10.1037/00332909.97.3.562

Martínez-Gómez, D., Eisenmann, J. C., Gómez-Martínez, S., Veses, A., Marcos, A., \& Veiga, O. L. (2010). Sedentary behavior, adiposity and cardiovascular risk factors in adolescents. The AFINOS study. Revista Española de Cardiología, 63, 277285. doi:10.1016/s0300-8932(10)70086-5

Mechanic, D., \& Hansell, S. (1987). Adolescent competence, psychological well-being, and self-assessed physical health. Journal of Health and Social Behavior, 28, 364-374.

Mielke, G. I., Brown, W. J., Nunes, B. P., Silva, I. C., \& Hallal, P. C. (2016). Socioeconomic correlates of sedentary behavior in adolescents: Systematic review and meta-analysis. Sports Medicine, 47, 61-75. doi:10.1007/s40279-016-0555-4

Richards, R., McGee, R., Williams, S. M., Welch, D., \& Hancox, R. J. (2010). Adolescent screen time and attachment to parents and peers. Archives of Pediatrics \& Adolescent Medicine, 164, 258-262. doi:10.1001/archpediatrics.2009.280

Sedentary Behaviour Research Network. (2012). Letter to the editor: Standardized use of the terms "sedentary" and "sedentary behaviours." Applied Physiology, Nutrition, and Metabolism, 37, 540-542. doi:10.1139/h2012-024.

Silva, D., Werneck, A. O., Collings, P., Tomeleri, C. M., Fernandes, R. A., Ronque, E., . . Cyrino, E. S. (2016). Cardiorespiratory fitness is related to metabolic risk independent of physical activity in boys but not girls from southern Brazil. American Journal of Human Biology, 28, 534-538 doi:10.1002/ajhb.22826

Spruit, A., Assink, M., van Vugt, E., van der Put, C., \& Stams, G. J. (2016). The effects of physical activity interventions on psychosocial outcomes in adolescents: A meta-analytic review. Clinical Psychology Review, 45, 56-71. doi:10.1016/j.cpr.2016.03.006

Sun, J.-W., Zhao, L.-G., Yang, Y., Ma, X., Wang, Y.-Y., \& Xiang, Y.-B. (2015). Association between television viewing time and all-cause mortality: A meta-analysis of cohort studies. American Journal of Epidemiology, 182, 908-916. doi:10.1093/aje/kwv164

Totland, T. H., Bjelland, M., Lien, N., Bergh, I. H., Gebremariam, M. K., Grydeland, M., . . Andersen, L. F. (2013). Adolescents' prospective screen time by gender and parental education, the mediation of parental influences. International Journal of Behavioral Nutrition and Physical Activity, 10, 89. doi:10.1186/1479-5868-10-89

Tremblay, M. S., LeBlanc, A. G., Kho, M. E., Saunders, T. J., Larouche, R., Colley, R. C., . . . Connor Gorber, S. (2011). Systematic review of sedentary behaviour and health indicators in school-aged children and youth. International Journal of Behavioral Nutrition and Physical Activity, 8, 98. doi:10.1186/1479-5868-8-98

Turi, B. C., Monteiro, H. L., Lemes, Í. R., Codogno, J. S., Lynch, K. R., Asahi Mesquita, C. A., \& Fernandes, R. A. (2018). TV viewing time is associated with increased all-cause mortality in Brazilian adults independent of physical activity. Scandinavian Journal of Medicine \& Science in Sports, 28, 596-603. doi:10.1111/sms.12882 